\title{
High levels of anti-SSA/Ro antibodies in COVID-19 patients with severe respiratory failure: a case-based review
}

\author{
High levels of anti-SSA/Ro antibodies in COVID-19
}

\author{
Hiroyuki Fujii ${ }^{1}$ Taisuke Tsuji ${ }^{1}$ Tatsuya Yuba ${ }^{1,2}$. Shunya Tanaka ${ }^{1}$ Yoshifumi Suga ${ }^{1}$. Aosa Matsuyama ${ }^{1}$. \\ Ayaka Omura $^{1} \cdot$ Shinsuke Shiotsu $^{1,3} \cdot$ Chieko Takumi $^{1,3} \cdot$ Seiko Ono $^{1,2} \cdot$ Masahito Horiguchi $^{4} \cdot$ Noriya Hiraoka $^{1}$
}

Received: 2 August 2020 / Revised: 18 August 2020 / Accepted: 20 August 2020 / Published online: 25 August 2020

(C) International League of Associations for Rheumatology (ILAR) 2020

\begin{abstract}
We treated two patients with severe respiratory failure due to coronavirus disease 2019 (COVID-19). Case 1 was a 73-year-old woman, and Case 2 was a 65-year-old-man. Neither of them had a history of autoimmune disease. Chest computed tomography scans before the antiviral therapy showed bilateral multiple patchy ground-glass opacities (GGO) consistent with COVID-19 pneumonia. The GGO regressed over the course of the antiviral treatment; however, new non-segmental patchy consolidations emerged, which resembled those of interstitial lung disease (ILD), specifically collagen vascular disease-associated ILD. We tested the patients' sera for autoantibodies and discovered that both patients had high anti-SSA/Ro antibody titers. In Case 1, the patient recovered with antiviral therapy alone. However, in Case 2, the patient did not improve with antiviral therapy alone but responded well to corticosteroid therapy (methylprednisolone) and made a full recovery. The relationship between some immunological responses and COVID-19 pneumonia exacerbation has been discussed previously; our discovery of the elevation of anti-SSA/Ro antibodies suggests a contribution from autoimmunity functions of the immune system. Although it is unclear whether the elevation of anti-SSA/Ro antibodies was a cause or an outcome of aggravated COVID-19 pneumonia, we hypothesize that both patients developed aggravated the COVID-19 pneumonia due to an autoimmune response. In COVID-19 lung injury, there may be a presence of autoimmunity factors in addition to the known effects of cytokine storms. In patients with COVID-19, a high level of anti-SSA/Ro52 antibodies may be a surrogate marker of pneumonia severity and poor prognosis.
\end{abstract}

Keywords Anti-SSA/Ro antibodies · Coronavirus disease 2019(COVID-19) · Corticosteroid · Severe acute respiratory syndrome coronavirus 2 (SARS-CoV-2)

\section{Introduction}

Since December 2019, the world has been confronted with the emergence of the novel coronavirus disease 2019 (COVID-

Hiroyuki Fujii

fujii0825@gmail.com

1 Department of Respiratory Medicine, Japanese Red Cross Kyoto Daiichi Hospital, 15-749 Honmachi, Higashiyama, Kyoto, Japan

2 Department of Infection Control, Japanese Red Cross Kyoto Daiichi Hospital, Kyoto, Japan

3 Department of Clinical Oncology, Japanese Red Cross Kyoto Daiichi Hospital, Kyoto, Japan

4 Department of Emergency Medicine, Japanese Red Cross Kyoto Daiichi Hospital, Kyoto, Japan
19) pandemic caused by severe acute respiratory syndrome coronavirus 2 (SARS-CoV-2). As of July 25, 2020, $15,581,009$ cases were reported, including 635,173 deaths in 216 countries [1]. To date, our hospital in Kyoto, Japan, has admitted 25 patients with confirmed COVID-19. This report describes two patients with severe respiratory failure due to COVID-19 that was associated with high levels of serum antiSSA/Ro antibodies, a type of antinuclear autoantibody that is associated with many autoimmune diseases.

\section{Case reports}

\section{Case 1}

A 78-year-old woman without a significant medical history presented to our emergency department with a fever and a 
productive cough. Her vital signs were body temperature $38.0{ }^{\circ} \mathrm{C}$, blood pressure $138 / 87 \mathrm{mmHg}$, heart rate $86 / \mathrm{min}$, and oxygen saturation $98 \%$ on ambient air. The findings on physical examination were unremarkable. Her laboratory tests revealed the following: white blood cell (WBC) count, 6080 cells/ $\mu \mathrm{L}$; lactate dehydrogenase (LDH), $322 \mathrm{U} / \mathrm{L}$; and C-reactive protein (CRP), $15.20 \mathrm{mg} / \mathrm{dL}$. A chest computed tomography $(\mathrm{CT})$ scan revealed bilateral multiple patchy ground-glass opacities (GGO) adjacent to the pleura (Fig. 1a). Because COVID-19 was strongly suspected, she was admitted to an isolation room. After obtaining a nasal swab specimen for polymerase chain reaction (PCR) testing for SARS-CoV-2, we started antimicrobial therapy with ceftriaxone and azithromycin. On the next day, her PCR test result was reported positive, so she was enrolled in a clinical trial, and was treated with favipiravir and ciclesonide combination antiviral therapy. However, her high fever continued and her respiratory condition gradually deteriorated, and oxygen inhalation became necessary on Day 3. On Day 4, her respiratory condition suddenly deteriorated further and her fever rose to $40.1^{\circ} \mathrm{C}$. Because she had specified that she did not want any attempt at resuscitation, we continued to supply the maximum possible oxygen with a reservoir facemask; however, her oxygen saturation remained $<90 \%$. Although her condition remained severe, we continued antiviral therapy and she gradually responded to the treatment. She was weaned from supplementary oxygen administration on Day 14 . SARS-CoV-2 PCR tests performed on Days 18 and 19 were both negative, indicating that she had recovered from SARSCoV-2 infection. A chest CT scan on Day 21 showed that the initial GGO had disappeared but revealed new bilateral nonsegmental patchy consolidations and the subpleural curvilinear shadows at the lower field of her right lung (Fig. 1b). Based on these findings, we considered a possible diagnosis of secondary interstitial lung disease (ILD), specifically collagen vascular disease-associated ILD, and on Day 22 we conducted tests for serum autoantibodies. The results are shown in Table 1. Even though she had no symptoms of collagen vascular disease, her anti-SSA/Ro antibody level was $203 \mathrm{U} /$ $\mathrm{mL}$. After her full recovery, she was discharged on Day 23, without sequelae.

\section{Case 2}

A 65-year-old man with a history of hypertension was transported via ambulance to a nearby hospital complaining of dyspnea. In the emergency department, his oxygen saturation on ambient air was $79 \%$ and his laboratory tests were WBC count $8500 / \mathrm{mm}^{3}$, LDH $501 \mathrm{U} / \mathrm{L}$, and CRP $10.44 \mathrm{mg} /$ dL. An arterial blood gas analysis with the administration of $6 \mathrm{~L} / \mathrm{min}$ of oxygen revealed $\mathrm{pH} 7.505, \mathrm{pCO}_{2} 34.5 \mathrm{mmHg}$, and $\mathrm{pO}_{2} 53.7 \mathrm{mmHg}$. A chest $\mathrm{CT}$ revealed bilateral multiple patchy GGO adjacent to the pleura suggestive of COVID-19 pneumonia (Fig. 2a). Because of the severity of his respiratory condition, he was intubated and mechanical ventilation and treatment with meropenem were initiated. On the next day his SARS-CoV-2 PCR test result, performed using a nasal swab specimen, was reported positive. His respiratory condition continued to deteriorate; on Day 5, he was transferred to our hospital for more advanced medical care. On arrival, the ventilator was set to Assist-Control ventilation plus volume guarantee mode (tidal volume, $450 \mathrm{~mL}$ ); respiratory rate $25 / \mathrm{min}$, fraction of inspiratory oxygen $\left(\mathrm{FiO}_{2}\right) 0.8$, and positive endexpiratory pressure (PEEP) $12 \mathrm{cmH}_{2} \mathrm{O}$. We immediately started empirical antiviral therapy with favipiravir, nafamostat mesylate, and hydroxychloroquine. He gradually responded to treatment, and his laboratory test results improved. Although his respiratory status improved, he still required mechanical ventilation. SARS-CoV-2 PCR tests of respiratory secretions on Days 8 and 11 were both negative. However, his CRP remained high $(5.71 \mathrm{mg} / \mathrm{dL})$ and his interleukin-6 (IL-6) rose to $109.2 \mathrm{pg} / \mathrm{mL}$ (normal range $<4.0 \mathrm{pg} / \mathrm{mL}$ ) on Day 12 . These results suggested that he had recovered from SARSCoV-2 infection, but some inflammatory reaction remained in his lungs, which interrupted the weaning from the ventilator. A chest CT scan on Day 12 revealed that the initial lesions had regressed, but new subpleural reticulations and consolidations reminiscent of organizing pneumonia $(\mathrm{OP})$ had appeared (Fig. 2b). From these findings, we suspected the presence of secondary ILD, particularly collagen vascular diseaseassociated ILD, conducted tests for serum autoantibodies. The results are shown in Table 1. Even though he had no history or symptoms of collagen vascular disease, his antiSSA/Ro antibody level was $442 \mathrm{U} / \mathrm{mL}$. We speculated that some immunological mechanism caused by viral infection could have led to his OP-like lung disease, and decided to use corticosteroid for further management. Intravenous methylprednisolone was initiated at a dose of $80 \mathrm{mg}$ for 3 days on Day 12 , followed by a dose of $40 \mathrm{mg}$ for the following 3 days. His respiratory condition improved dramatically in response to the methylprednisolone treatment. Even though tracheotomy was necessary because of long-term intubation management, it was possible to discontinue oxygen administration on Day 17, and he was transferred back to the previous hospital. His chest CT scan before transfer showed that the subpleural reticulations and consolidations had improved (Fig. 2c).

\section{Discussion}

Both patients experienced a rapid deterioration of their respiratory condition that met the Berlin definition of acute respiratory distress syndrome (ARDS). COVID-19-associated ARDS may be induced by a cytokine storm, mainly by IL-6, an excessive immune defense response, and is usually fatal. SARS-CoV-2 infection can activate NF-kB and STAT3 
Table 1 Serum autoantibodies in COVID-19 patients after the onset of suspected interstitial lung disease

\begin{tabular}{|c|c|c|c|}
\hline & Case 1 & Case 2 & Normal range \\
\hline Antinuclear antibodies (ANA) & 80 & $<40$ & \multirow[t]{7}{*}{$<40$ (titer) } \\
\hline Homogenous pattern & 40 & $<40$ & \\
\hline Speckled pattern & 80 & $<40$ & \\
\hline Nucleolar pattern & $<40$ & $<40$ & \\
\hline Peripheral pattern & $<40$ & $<40$ & \\
\hline Discrete speckled or centromere pattern & $<40$ & $<40$ & \\
\hline Cytoplasmic pattern & 40 & $<40$ & \\
\hline $\begin{array}{l}\text { Anti-single-stranded DNA antibodies } \\
\text { (anti-ss-DNA antibodies) }\end{array}$ & 18 & $<10$ & $<25 \mathrm{AU} / \mathrm{mL}$ \\
\hline $\begin{array}{l}\text { Anti-double-stranded DNA antibodies } \\
\text { (anti-ds-DNA antibodies) }\end{array}$ & $<10$ & $<10$ & $<12 \mathrm{IU} / \mathrm{mL}$ \\
\hline Anti-U1-RNP antibodies & $<2.0$ & $<2.0$ & $<10 \mathrm{U} / \mathrm{mL}$ \\
\hline Anti-Sm antibodies & $<1.0$ & $<1.0$ & $<10 \mathrm{U} / \mathrm{mL}$ \\
\hline $\begin{array}{l}\text { Anti-SSA/Ro52 } \cdot \text { Ro60 antibodies } \\
\quad \text { (anti-SSA/Ro antibodies) }\end{array}$ & 203 & 442 & $<10 \mathrm{U} / \mathrm{mL}$ \\
\hline Anti-SSB/La antibodies & $<1.0$ & 37.2 & $<10 \mathrm{U} / \mathrm{mL}$ \\
\hline Anti-Scl-70 antibodies & 10.7 & $<1.0$ & $<10 \mathrm{U} / \mathrm{mL}$ \\
\hline Rheumatoid factor (RF) & 16 & 16 & $<15 \mathrm{U} / \mathrm{mL}$ \\
\hline $\begin{array}{l}\text { Anti-cyclic citrullinated peptide antibodies } \\
\text { (anti-CCP antibodies) }\end{array}$ & $<0.6$ & $<0.6$ & $<4.5 \mathrm{U} / \mathrm{mL}$ \\
\hline $\begin{array}{l}\text { Myeloperoxidase-anti-neutrophil cytoplasmic } \\
\text { antibodies (MPO-ANCA) }\end{array}$ & $<1.0$ & $<1.0$ & $<3.5 \mathrm{U} / \mathrm{mL}$ \\
\hline $\begin{array}{l}\text { Serine proteinase3-anti-neutrophil cytoplasmic } \\
\text { antibodies (PR3-ANCA) }\end{array}$ & $<1.0$ & $<1.0$ & $<3.5 \mathrm{U} / \mathrm{mL}$ \\
\hline $\begin{array}{l}\text { Anti-amino acyl-tRNA synthetases antibodies } \\
\text { (anti-ARS antibodies) }\end{array}$ & $<5.0$ & $<5.0$ & $<25$ (titer) \\
\hline $\begin{array}{l}\text { Anti- melanoma differentiation associated gene } 5 \\
\text { antibodies (anti-MDA5 antibodies) }\end{array}$ & $<5.0$ & $<5.0$ & $<32$ (titer) \\
\hline Anti-Mi 2 antibodies & $<5.0$ & $<5.0$ & $<53$ (titer) \\
\hline
\end{tabular}

pathways and lead to hyper-activation of IL-6 signaling [2]. IL-6 is a multifunctional cytokine, identified as a T cellderived cytokine that acts on $\mathrm{B}$ cells to induce antibody production, and is involved in the pathogenesis of many autoimmune and inflammatory diseases [3]. In patients with SARS$\mathrm{CoV}$, which is genetically similar to SARS-CoV-2, SARS$\mathrm{CoV}$ antigen has been shown to cross-react with autoantibodies from patients with autoimmune diseases [4]. Based on this background knowledge and the clinical course of the disease in both patients, we presumed that the aggravation of COVID-19 pneumonia was related to an autoimmune response and tested both patients for serum autoantibodies to investigate autoimmune characteristics of severe COVID-19 pneumonia. Both patients had high serum levels of anti-SSA/ Ro antibodies. Autoantibodies directed against SSA/Ro autoantigens were originally identified in patients with Sjögren's syndrome, but these antibodies are now recognized as non-organ-specific and non-disease-specific. One report showed that $60 \%$ of the individuals who have anti-SSA/Ro antibodies were clinically healthy [5]. There are two types of SSA/Ro autoantigens with different molecular weights: Ro52 antigens (52 kDa) and Ro60 antigens (60 kDa) [6]. We were unable to test for autoantibodies in our hospital and, as outside laboratories do not accept specimens from patients with COVID-19, we were unable to have our patients tested until they were confirmed as SARS-CoV-2 RNA-negative on PCR. The outside laboratory measured Ro52 and Ro60 antibodies together, so we were unable to determine each value separately. In patients with collagen vascular disease, the presence of anti-SSA/Ro52 antibodies is associated with ILD. In patients with Sjögren's syndrome, the risk of developing ILD is higher if anti-SSA/Ro52 antibodies are present [7], and in patients with polymyositis and dermatomyositis, the level of anti-SSA/ Ro52 autoantibodies is strongly associated with the severity of ILD and prognosis [8]. We consider that the lung pathophysiology of our two patients resembled collagen vascular disease-associated ILD based on their CT scan findings after antiviral treatment and elevated serum autoantibodies. Furthermore, in Case 2, the responsiveness of his lung condition to steroids is also consistent with collagen vascular disease-associated ILD. Therefore, we hypothesize that in patients with COVID-19, a high level of anti-SSA/Ro52 
a

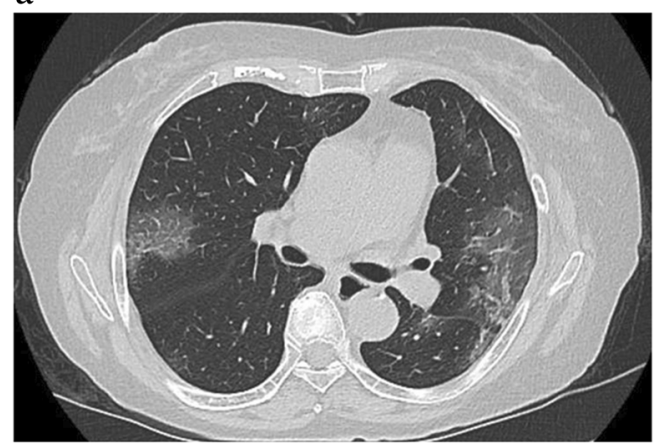

b

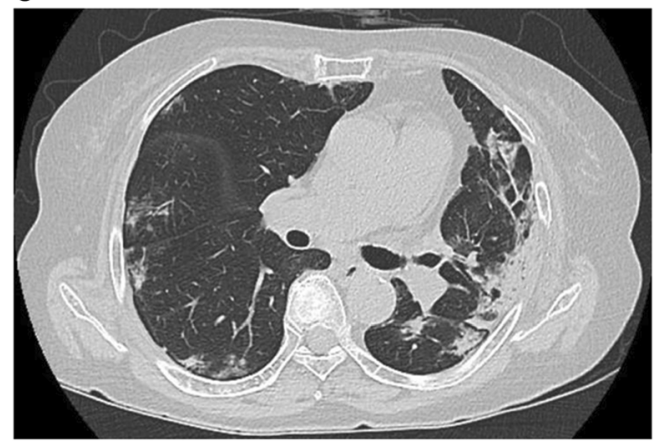

Fig. 1 Imaging findings on Patient 1, a 78-year-old woman with COVID19 pneumonia. a A chest computed tomography scan performed on admission shows bilateral multiple patchy ground-glass opacities adjacent to the pleura. $\mathbf{b}$ A chest computed tomography scan performed on Day 21 shows that the ground-glass opacities seen on admission have disappeared. New bilateral non-segmental patchy consolidations have appeared, and there are subpleural curvilinear shadows at the lower field of the right lung

antibodies may be a marker of pneumonia severity and poor prognosis, just as a high level of anti-SSA/Ro52 antibodies is a marker of poor prognosis in patients with collagen vascular disease-associated ILD, including Sjögren's syndrome, polymyositis, and dermatomyositis. However, SSA/Ro antibodies are detected in 0.2 to $2.7 \%$ of healthy individuals (this is especially true in individuals such as our older patients) [5, 9]; therefore, it cannot be ruled out that the presence of SSA/ Ro antibodies in the two patients may have been an incidental event of no clinical significance. An important limitation of this report is that we were unable to test for autoantibodies before the onset of COVID-19 and at the time of admission. Although it is unclear whether the elevation of anti-SSA/Ro antibodies was a cause or a result of the COVID-19 pneumonia aggravation, these findings suggest that there is a strong association between an aggravation of COVID-19 pneumonia and an autoimmune response. The RECOVERY Trial revealed that the steroid drug, dexamethasone, reduces the risk of death in patients with severe COVID-19 pneumonia [10]. This trial supports the hypothesis that an immunological mechanism is involved in the aggravation of COVID-19. Furthermore, the finding that anti-SSA/Ro antibodies are

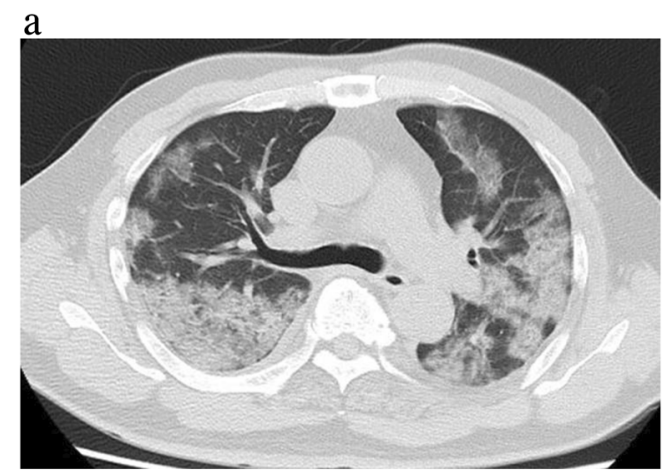

b
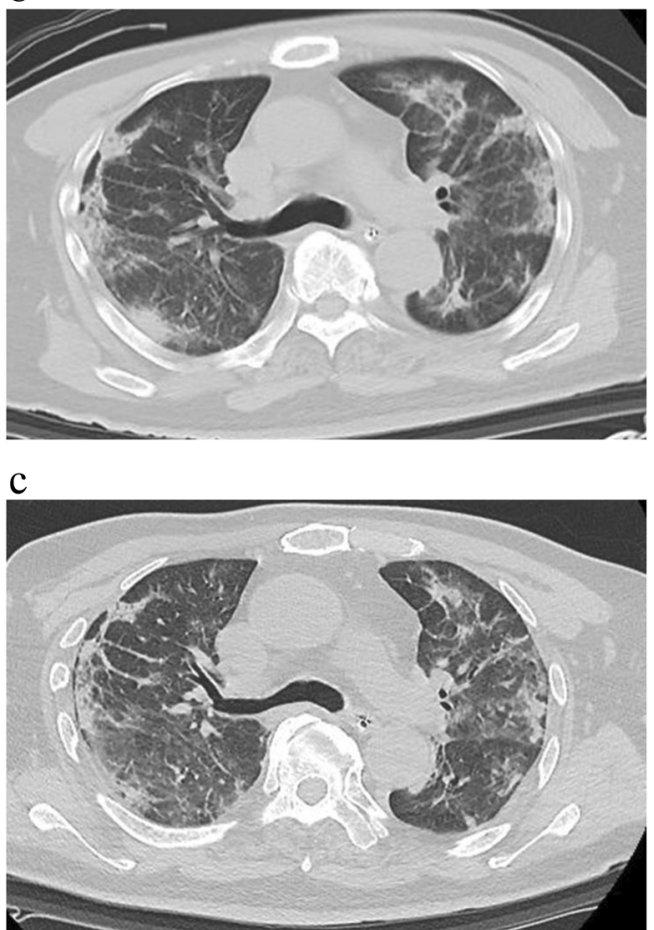

Fig. 2 Imaging findings on Patient 2, a 65-year-old man with COVID-19 pneumonia. a A chest computed tomography scan performed on admission to the first hospital shows bilateral multiple patchy cottonlike ground-glass opacities adjacent to the pleura. b A chest computed tomography scan performed on Day 12 shows that the initial lesions have regressed, but new subpleural reticulations and consolidations reminiscent of organizing pneumonia had appeared. c A chest computed tomography scan performed on Day 17, prior to discharge, shows that the subpleural reticulations and consolidations are less marked

specifically elevated may suggest a contribution from autoimmunity factors of the immune system. In COVID-19 lung injuries, there may be an autoimmunity presence among the known effects of cytokine storms. Both patients recovered and did not have any residual signs of collagen vascular disease; however, we plan to continue to monitor them carefully for signs of collagen vascular disease. Further research is required to elucidate the contribution of autoimmunity factors in COVID-19 and determine the relationship between COVID19 progression and high levels of anti-SSA/Ro antibodies. 
Authors' contributions All authors contributed to the study conception and design. Material preparation, data collection, and analysis were performed by Hiroyuki Fujii and Taisuke Tsuji. The first draft of the manuscript was written by Hiroyuki Fujii, and all authors commented on previous versions of the manuscript. All authors read and approved the final manuscript.

Data availability Data sharing not applicable to this article as no datasets were generated or analyzed during the current study.

\section{Compliance with ethical standards}

Disclosures None.

Ethical approval In our hospital, even case reports must be approved by the Institutional Review Board. Our case report has been approved by the hospital's ethics review committee and has an approval number of 1062 .

\section{Consent to participate Not applicable.}

Consent for publication Both patients have provided written informed consent for the publication of their case descriptions.

Code availability Not applicable.

\section{References}

1. World Health Organization (2020) Coronavirus disease (COVID19) situation reports. Situation Report-187. https://www.who.int/ emergencies/diseases/novel-coronavirus-2019/situation-reports/. Accessed 25 July 2020

2. Toshio H, Masaaki M (2020) COVID-19: a new virus, but a familiar receptor and cytokine release syndrome. Immunity 52:731-733

3. Hirano T, Yasukawa K, Harada H, Taga T, Watanabe Y, Matsuda T, Kashiwamura S, Nakajima K, Koyama K, Iwamatsu A,
Tsunasawa S, Sakiyama F, Matsui H, Takahara Y, Taniguchi T, Kishimoto T (1986) Complementary DNA for a novel human interleukin (BSF-2) that induces B lymphocytes to produce immunoglobulin. Nature 324:73-76

4. Wang Y, Sun S, Shen H, Jiang L, Zhang M, Xiao D, Liu Y, Ma X, Zhang Y, Guo N, Jia T (2004) Cross-reaction of SARS-CoV antigen with autoantibodies in autoimmune diseases. Cell Mol Immunol 1:304-307

5. Nobuhide H, Masahiro K, Kunihiro N, Daisuke S, Tomoko N, Sahoko M, Seiji K, Shunichi K (2008) Prevalence of diseasespecific antinuclear antibodies in general population: estimates from annual physical examinations of residents of a small town over a 5-year period. Mod Rheumatol 18:153-160

6. Chan EK, Hamel JC, Buyon JP, Tan EM (1991) Molecular definition and sequence motifs of the $52-\mathrm{kD}$ component of human SS-A/ Ro autoantigen. J Clin Invest 87:68-76

7. Buvry C, Cassagnes L, Tekath M, Artigues M, Pereira B, Rieu V, Le Guenno G, Tournadre A, Ruivard M, Grobost V (2020) AntiRo52 antibodies are a risk factor for interstitial lung disease in primary Sjögren syndrome. Respir Med 163:105895. https://doi. org/10.1016/j.rmed.2020.105895

8. Sabbagh S, Pinal-Fernandez I, Kishi T, Targoff IN, Miller FW, Rider LG, Mammen AL; Childhood Myositis Heterogeneity Collaborative Study Group (2019) Anti-Ro52 autoantibodies are associated with interstitial lung disease and more severe disease in patients with juvenile myositis. Ann Rheum Dis 78:988-995

9. de Vlam K, De Keyser F, Verbruggen G, Vandenbossche M, Vanneuville B, D'Haese D et al (1993) Detection and identification of antinuclear autoantibodies in the serum of normal blood donors. Clin Exp Rheumatol 11:393-397

10. RECOVERY Collaborative Group, Horby P, Lim WS, Emberson JR, Mafham M, Bell JL, Linsell L et al (2020) Effect of dexamethasone in hospitalized patients with COVID-19: preliminary report. N Engl J Med. https://doi.org/10.1056/NEJMoa2021436

Publisher's note Springer Nature remains neutral with regard to jurisdictional claims in published maps and institutional affiliations. 